\title{
THE SIGNIFICANCE OF THE ABATTOIR IN SALMONELLA INFECTION IN BRADFORD
}

\author{
By V. P. McDONAGH \\ Deputy Medical Officer of Health, Bradford* \\ AND H. G. SMITH \\ Public Health Laboratory, Bradford \\ (With 1 Figure in Text)

\section{INTRODUCTION}

Of the common domestic animals slaughtered for human consumption, pigs are much more frequently found to be infected with salmonella organisms than sheep or cattle. Hormaeche \& Salsamendi (1936) found that about $50 \%$ of the batches of mesenteric glands from apparently normal pigs in Uraguay contained these organisms. In this country Scott (1940) undertook a similar investigation and isolated Salmonella from more than one-third of the samples examined. The more extensive survey of infection in pigs carried out by the Emergency Public Health Laboratory Service during the Second World War (Report, 1947) yielded similar results. This report had particular interest in that it revealed the presence of a much wider range of serotypes (some not previously found in Europe) than had hitherto been found in pigs slaughtered in this country, and there was good evidence to relate these findings to the feeding of pigs with condemned imported dried egg preparations. In a later survey (Report, 1955a) the infection rates were lower and the range of serotypes narrower.

Although in particular outbreaks of salmonella food poisoning the evidence may point to the consumption of infected beef or mutton, an examination of the literature indicates that pork-meat dishes are by far the most commonly incriminated. The investigation reported in this communication arose out of a number of family and sporadic outbreaks of food poisoning in Bradford in the autumn of 1954 due to Salm. bovis-morbificans. There was strong epidemiological evidence that the cause of the outbreak was due to infected pork and preliminary examinations at the Bradford slaughter-house resulted in a number of isolations of Salm. bovismorbificans from pig offal. This confirmed the view that the slaughter-house was a potential source of salmonella infections in the local population. It was, therefore, decided to investigate the problem more fully, and to endeavour to relate the incidence of salmonella organisms in pigs before slaughter to the bacteriological findings in the slaughter-halls, and finally to outbreaks of salmonella food poisoning in the area in which the pork and offal were distributed. Cattle, sheep and pigs were included in the preliminary investigation but for the purpose of this

\footnotetext{
* Now Medical Officer of Health, Keighley and Div. M.O. W.R.C.C.
} 
communication the records have been limited to examination of pigs because of their greater importance as sources of salmonella infection.

Although possibly varying in some detail the procedures employed in the Bradford abattoir are not substantially different from those generally used. Either the captive bolt pistol or the electric tongs are used for stunning. After bleeding, the animals are depilated in scalding tanks and then hung head downward. Buckets of water from a running tap, are thrown over the carcasses and the excess water is removed by a wiping cloth used successively on each animal. The opening and evisceration is performed with dexterity and speed, but there is always an opportunity for surface contamination of the carcass and the organs with faecal material and indeed, its transfer to other carcasses in the successive handling.

It seemed clear from previous investigations in which a significant proportion of mesenteric glands of slaughtered pigs were found to be infected with salmonella organisms that many animals coming to slaughter must be so suffering, without showing any clinical symptoms. Indeed, incidences are on record where apparently healthy animals have been found to have been suffering from a generalized salmonella infection. Other factors being equal, it appeared likely that the extent of surface contamination of carcasses, as a result of slaughter-house procedures, would be related to the proportion of infected animals (and to the degree of infection) to non-infected animals in any batch slaughtered during a particular session.

Galton, Smith, McElrath \& Hardy (1954) showed that significant proportions of the animals might be infected on the farm and that during the period of holding immediately before slaughter, when the pigs might be crowded together in pens for $48 \mathrm{hr}$., all the animals were heavily exposed to salmonella infections. Scott (1940) drew attention to the possibilities of cross-infection in the lairage. The extent of this build-up of infection would depend on local conditions and where the numbers of animals arriving at the abattoir were in excess of the facilities of the slaughterhouse, as happened from time to time in Bradford, and when they were kept too long in the lairage before slaughter. Under such conditions there was, therefore, a very real danger of a serious spread of infection and with so many opportunities in the slaughter-house for surface contamination of the carcasses a high proportion of the meat distributed might be heavily infected with salmonellae.

\section{MATERIAL AND METHODS}

While it might have been of interest to make bacteriological examination of the pigs on the farms (North of England, Border Country and East Anglia) sending animals to the Bradford abattoir this was not feasible. At the same time it was felt that the results of the examination of animals immediately on arrival compared with the results immediately before slaughter would give valuable information about the build-up of infection in the lairage.

Bacteriological examination of the following material was undertaken:

(1) Rectal swabs from various batches of pigs on arrival from the farms (consignments not identified with any particular farm).

(2) Faecal specimens from lairage floors. 
(3) Rectal swabs from various batches of pigs immediately before slaughter.

(4) Culture of specimens of liver spleen and mesenteric glands immediately after dressing of carcass without prior sterilization of the tissue surface.

(5) Culture of specimens of liver, spleen and mesenteric glands before and after sterilization of surface of tissues.

(6) Miscellaneous examination of rinse waters, floor, offal tables and sides of drinking troughs in the abattoir.

Rectal swabs and faecal specimens were cultured overnight in selenite broth and then plated out on deoxycholate-citrate-agar by the usual technique for isolation of salmonella organisms.

Tissue specimens were collected at the abattoir immediately after slaughter, placed in separate sterile universal containers and transported directly to the laboratory. For the untreated tissues 15-20 ml. selenite broth was added and the container incubated for $48 \mathrm{hr}$.; subcultures at 24 and $48 \mathrm{hr}$. were plated on deoxycholate-citrate-agar.

Tissues to be treated were first rinsed in $10 \mathrm{ml}$. selenite broth and then dipped into boiling water for $10 \mathrm{sec}$. They were then cut with sterile scissors into small pieces which were placed into a second container of selenite broth. Cultures of both the rinses and scalded specimens were then examined as before.

The miscellaneous specimens were collected as swabs or as fluids. These were incubated in selenite broth and then plated out in the usual way.

\section{RESULTS}

Rectal swabs of 171 pigs taken immediately after arrival at the lairage showed that $2.9 \%$ of the animals were excreting salmonella organisms, whereas bacteriological examination of 371 animals, after 1-7 days or even longer in the lairage, showed that $13.5 \%$ were harbouring salmonellae, $36 \%$ of which were Salm.typhi-murium and $64 \% \mathrm{Salm}$. derby. The figures from the two investigations are not strictly comparable since the examinations covered different periods of the year. Nevertheless, they are sufficiently striking to indicate how an infection can be built up in the lairage especially when the animals have to be fed during the longer holding periods. Salm. typhi-murium and Salm. derby were found together in the same animal on several occasions after a prolonged stay in the lairage, but Salm. derby only was found in the few newly arrived animals that were excreting salmonellae. Salm. typhi-murium and Salm. derby were also isolated from the faeces lying about the lairage.

Table 1 , which gives the results of the bacteriological examinations of untreated livers, spleens, and mesenteric glands, shows that of the tissues examined nearly one-quarter were contaminated with salmonella organisms.

The consolidated figures for several series of examinations totalling 296 tissues for both surface contaminations and true tissue infections show that while the surface contamination rate was $18 \%$ the tissue infection rate was $4 \%$.

Miscellaneous examinations in the abattoir were carried out from time to time on swabs, rinse waters, offal tables and various pieces of equipment. Except on 


\section{Table 1. The results of examinations from pigs during 1954-56}

\begin{tabular}{|c|c|c|c|c|c|c|c|c|}
\hline \multirow[b]{2}{*}{ Year } & \multirow{2}{*}{$\begin{array}{l}\text { No. of tissue } \\
\text { specimens of } \\
\text { liver, spleen } \\
\text { or glands } \\
\text { examined }\end{array}$} & \multicolumn{6}{|c|}{ Salmonella types isolated } & \multirow[b]{2}{*}{ Totals } \\
\hline & & $\begin{array}{l}\text { typhi- } \\
\text { murium }\end{array}$ & $\begin{array}{c}\text { bovis- } \\
\text { morbificans }\end{array}$ & derby & $\begin{array}{l}\text { man- } \\
\text { hattan }\end{array}$ & muenchen & anatum & \\
\hline 1954 & 156 & 15 & 5 & - & - & - & 一 & 20 \\
\hline 1955 & 704 & 18 & 1 & 38 & 1 & - & - & 58 \\
\hline 1956 & 2001 & 362 & 一 & 263 & - & 2 & I & 628 \\
\hline Totals & 2861 & 395 & 6 & 301 & 1 & 2 & $\mathbf{l}$ & 706 \\
\hline
\end{tabular}

one occasion when Salm. bovis-morbificans was isolated from fat scrapings off a window ledge the isolations were about equally divided between Salm. typhimurium and Salm. derby. Both these organisms were isolated from pigs during their examination in the waiting pens with significant frequency and it is, therefore, not surprising that they comprised the bulk of the isolations from the various examinations in the slaughter-house.

\section{SALMONELLA INFECTIONS IN THE BRADFORD POPULATION FROM 1954-56}

A total of 5417 cases of diarrhoea were notified or ascertained during this period, including notifications of dysentery, salmonella infection, food poisoning, paratyphoid fever and infective enteritis. These, however, represented a small proportion of the total number in the community as approximately $30 \%$ of the general practitioners notify these diseases and only $5 \%$ do so regularly. Although reliable information with regard to the absolute incidence of salmonella infections in the population of Bradford is lacking, in recent years the records of isolations of salmonellae in the Public Health Laboratory from faecal specimens of patients offer some indication of the prevalence of the condition. The figures do not include any very large outbreaks and, for the most part, the specimens came from sporadic cases, small family outbreaks, and symptomless excreters found during investigations of these cases. Fig. 1 and Table 2 show that there was a very significant increase in the year 1954, as compared with previous years, in the total number of isolations and that the high level was maintained over the 2 succeeding years.

In attempting to relate the incidence of salmonella infections in the Bradford populations to the figures obtained from the bacteriological examination of pigs immediately before slaughter, and those obtained from the examination of tissue specimens from the slaughter-house, one might be tempted to assume that the high incidence of salmonella infections in the abattoir in 1954 would explain the sudden increase in the number of infections in the human population. While this assumption may be true the evidence is not sufficiently complete, since slaughterhouse figures for the previous years are not available for pigs, and without such evidence it is not safe to assume that there was a sudden increase in salmonella infection of pigs coming to slaughter. When we come, however, to examine the records of primary salmonella isolations in Bradford during the years 1950-56, 




Fig. 1. Incidence of salmonella infection in the population in Bradford from 1950-56.

Table 2. Salmonella serotypes isolated from patients in Bradford area.

$$
\begin{aligned}
& \text { Numbers of patients affected }
\end{aligned}
$$

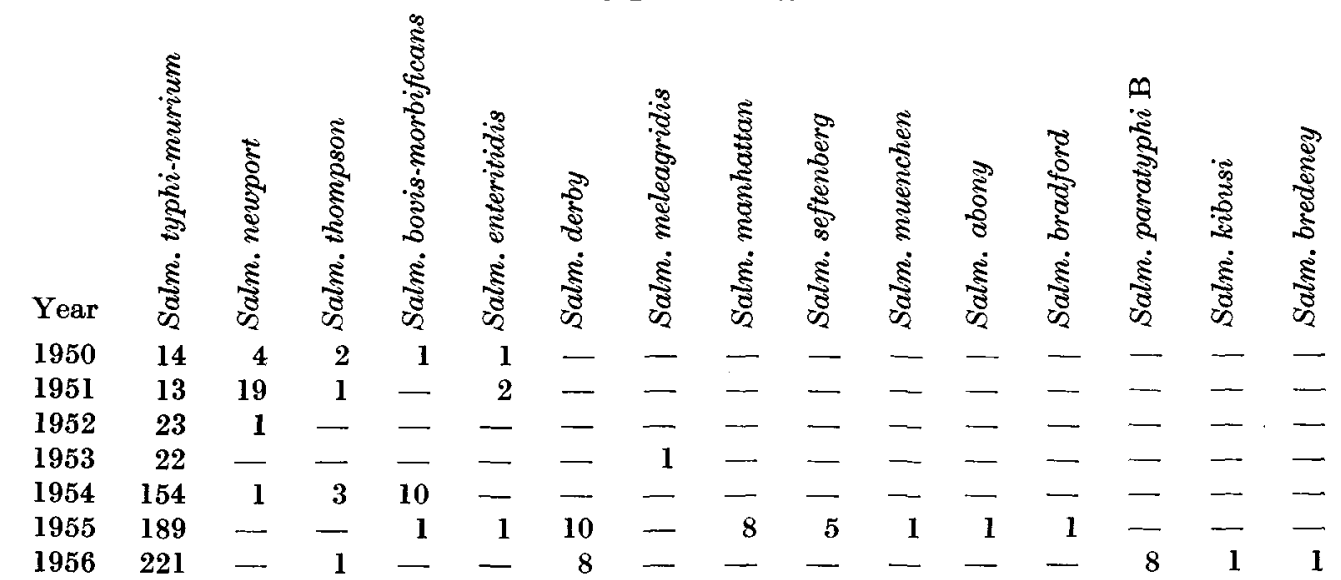

In 1954 slaughter-house isolations included a fow Salm. bovis-morbificans. There was an outbreak in the city due to this organism which was traced to meat products infected with this salmonella serotype. About a third of the Salm.typhi-murium infections were related to the consumption of infected pork pies from one bakery.

In 1955 and 1956 the slaughter-house isolations were almost entirely confined to Salm. typhi-murium and Salm. derby. 
there seems to be evidence to support the thesis that salmonella infections of the local population could be related to infected meat products originating from the Bradford slaughter-house.

Throughout the years Salm. typhi-murium heads the list of infecting organisms in order of frequence. This is to be expected as it is universally the commonest salmonella responsible for food poisoning. Salm. derby is not a common cause of gastro-enteritis in this country and this type was not isolated from any patient during the years 1950-54, but in 1955 there were ten isolated incidents due to this organism and in the same year it was found frequently in the slaughter-house.

In the next year the number of human infections appeared to be of the same order, and pigs arriving at the slaughter-house were found to be infected with Salm. derby. Although there were a few mild cases of food poisoning due to this organism there was no serious outbreak in spite of the heavy contamination found in the slaughterhouse. In August 1956, when a high proportion of pigs were found to be excreting Salm.typhi-murium and Salm. derby and the slaughter-house contamination of the meat products with both organisms was particularly heavy, a case of infection due to Salm. typhi-murium occurred in a butcher in a well-conducted meat-products factory. In the course of examining the staff of this establishment three members were found to be excreting Salm.typhi-murium and two Salm. derby, though there was no evidence of any infection in the city that could be associated with the consumption of the firm's products.

To obtain information which might show some relationship between human infections with Salm. typhi-murium and the abattoir isolations, representative collections of cultures from both sources were sent to the Central Enteric Reference Laboratory, Colindale, for phage typing. The results obtained are shown in Table 3.

Table 3. Comparison of phage types of Salm. typhi-murium from samples of cases and symptomless excreters with samples of isolations from abattoir specimens

\begin{tabular}{|c|c|c|c|c|}
\hline Year & $\begin{array}{c}\text { No. of cases } \\
\text { and symptomless } \\
\text { excreters }\end{array}$ & Phage types & $\begin{array}{l}\text { No. of } \\
\text { abattoir } \\
\text { isolations }\end{array}$ & Phage types \\
\hline 1954 & $\begin{array}{r}10 \\
1 \\
-\end{array}$ & $\begin{array}{l}2 c \\
1 a \\
-\end{array}$ & $\begin{array}{r}11 \\
3 \\
5\end{array}$ & $\begin{array}{c}2 c \\
1 a \\
\text { Untypable }\end{array}$ \\
\hline 1955 & $\begin{array}{r}22 \\
5 \\
8\end{array}$ & $\begin{array}{c}\text { Untypable } \\
\qquad 2 c \\
2\end{array}$ & $\begin{array}{l}10 \\
-\end{array}$ & $\begin{array}{c}\text { Untypable } \\
- \\
-\end{array}$ \\
\hline 1956 & $\begin{array}{r}21 \\
6 \\
8 \\
2 \\
1 \\
3\end{array}$ & $\begin{array}{c}2 b \\
2 c \\
4 \\
1 a \\
2 a \\
\text { Untypable }\end{array}$ & $\begin{array}{r}4 \\
6 \\
2 \\
- \\
-\end{array}$ & $\begin{array}{c}2 b \\
2 c \\
\text { Untypable } \\
- \\
-\end{array}$ \\
\hline
\end{tabular}

It will be seen that the evidence obtained is by no means conclusive; nevertheless, it offers some support for a relationship. In 1954 the finding of ten phage type $2 c$ out of eleven cultures from the population and eleven of the same phage type out 
of nineteen abattoir cultures examined is suggestive evidence. Untypable strains obviously present difficulties and little can be said about the twenty-two and ten untypable strains isolated during 1955 , though possibly all or most may have belonged to the same parent type. In 1956 phage type $2 b$ was of particular interest, as it appeared about the same time in the second half of the year in both the human population and pig tissues.

Some incidents on investigation gave clear evidence that the source of the Salm. typhi-murium infection was not the slaughter-house. Two such outbreaks in June 1956 due to phage type 4 were traced to two bakeries. One of them was also implicated in 1955 and in both years widespread contamination with the same phage type was found among the samples of English frozen eggs used for the preparation of the various products sold by the bakery.

An outbreak of food poisoning due to Salm. typhi-murium, phage type $2 c$ occurred in November 1954 in which the evidence indicated that the primary source of the outbreak was the use of infected pork at a pie manufacturing establishment. The study of small family outbreaks sometimes yielded information of value. For example, a housewife purchased a joint of pork on a Saturday afternoon and part was consumed hot on theSunday. On Monday cold roast pork was served for luncheon and cold pork sandwiches for tea. Severe symptoms in both the husband and wife developed at 10 o'clock on Tuesday morning. Salm. typhi-murium phage type $2 b$ was isolated from the two patients and this same phage type was prevalent during the period in question in the slaughter-house.

\section{DISCUSSION}

In the course of investigations into the cause of salmonella infections in Bradford during the years 1954-56 we have gathered evidence to incriminate the abattoir as the most important source of salmonella infection and pigs as the main animal reservoir. However, the low incidence of salmonella infections before this period and the greatly raised incidence recently suggests that heavy infection of the abattoir is a recent event. It may be, then, more than a coincidence that this investigation commenced shortly after derationing of meat came into force. The effect on the abattoir has been an increase in the number of animals sent in for slaughter to meet public demand, and the overcrowding of the lairages has provided the opportunity for a build-up of infection. The abattoir situation, however, cannot be divorced from the salmonella infection of pigs before they arrive at the abattoir, but what remote factors may have been responsible for the more widespread infection of pigs are matters for conjecture. Bischoff (1956) has drawn attention to the increase of rare types of salmonellae in Germany and has suggested that imported fish meal may be a vehicle of salmonella organisms.

The importance of meat products as vehicles of salmonella infections has been emphasized in various Reports $(1955 b, 1956)$. Cherry, Scherago \& Weaver (1943) isolated salmonellae from different kinds of retail meat products and Galton, Lowery \& Hardy (1954) found a large proportion of fresh and smoked sausage infected with salmonellae. Salmonella infection in the Bradford abattoir has been 
so extensive that infected flesh or offal must have been introduced into many homes and, no doubt, was directly responsible for numbers of family and sporadic infections. The outbreak in 1954 due to infected pork pies is an example of the dramatic event that may occur when salmonella organisms find a favourable situation for multiplication. However, this is the only instance that we have encountered of a large outbreak connected with infected pork from the abattoir. In contrast frozen eggs in a bakery appeared to result in a long-continued and widespread contamination of ingredients and utensils as well as confectionery and meat pies. Infected pork must have been introduced also into many manufacturing premises and have infected cooked food products, but investigations of possible outbreaks suggested thay these infections were probably transient. Food handlers are exposed to considerable risk of infection and though most of them discovered in this investigation were symptomless excreters they presented a difficult administrative problem.

Most of the cases that occurred during the past 3 years were due to Salm.typhimurium, which is in accordance with the finding of large numbers of the same type of organism in the abattoir. However, that gross infection of pigs may have little effect on the community is indicated by the small number of cases infected with Salm. derby. It is interesting that experiments carried out on human volunteers by McCullough \& Eisele (1951) showed that Salm. derby did not produce symptoms in dosages less than 15,000,000 organisms, while Salm. newport produced illness in one man out of six receiving 152,000 organisms and in three out of six receiving each 1,350,000 organisms. Salm. bareilly gave somewhat similar results to Salm. newport. There may, therefore, be differences in pathogenicity among different salmonella types and even among different strains. Also, experiments by Miller \& Ramsden (Ministry of Health Report, 1955) have indicated that Salm. bovis morbificans has a greater resistance to heating than Salm.typhi-murium. Factors such as pathogenicity and heat tolerance may be, therefore, of considerable importance in the relationship of abattoir infection to the community, and may assign a greater significance to more elusive abattoir infection of which Salm. manhattan infection is believed in this investigation to be an example.

During the year $\mathbf{1 9 5 5}$ the number of sporadic cases due to salmonellae in England and Wales showed a striking increase over those in 1954 (Reports, 1955b, 1956). The diversity of salmonella types in the Bradford abattoir suggests that infection in pigs is more than a local problem. On the other hand, investigations carried out on a small scale in other abattoirs in the West Riding have shown little or no evidence of salmonella infection in pigs. It may be that salmonella infection is widely scattered in farms and is variable in time and prevalence but cumulatively highly significant. In the light of the Bradford findings it would seem that more information is required on the incidence of salmonellae in pigs in different parts of the country. These animals number between four and five million and may, therefore, constitute an important reservoir of infection.

The problem of controlling infection in the abattoir must give concern to all who have responsibility for the provision of clean food. The most practical step would be to shorten the period the pigs spend in the lairage. Early in 1957 the provisional 
approval of the Ministry of Agriculture, Fisheries and Food was obtained to a byelaw which would ensure that pigs would be slaughtered as soon as practicable after arrival, and in any case within a period of $48 \mathrm{hr}$. from being first brought into the slaughter-house. However, a fully satisfactory method must embrace a measure of control on the pig farms together with new abattoirs built on up-to-date hygienic lines.

\section{SUMMARY}

1. During the years 1954-56 large number of salmonellae, comprising six serotypes and a number of Salm. typhi-murium phage types, were isolated at the Bradford abattoir.

2. Most of the cultures were derived from pigs; the animals presented no sign of clinical illness.

3. Human salmonella infections in Bradford over the same period were closely related to the abattoir findings.

4. It seems probable that individual pigs are infected on the farms and when brought to the abattoir may infect others in the lairages.

5. Limiting the duration of stay in the lairages and prevention of overcrowding may substantially reduce the proportion of animals found infected at slaughter.

We wish to express our thanks to Dr John Douglas, Medical Officer of Health, Bradford, for his interest and encouragement in this investigation and to $\mathrm{Mr} \mathrm{F}$. H. Myres, Mr J. Noble, Mr E. Root and Mr R. Butterfield of the Bradford Health Department for their enthusiastic help. Thanks are also due to Dr Joan Taylor and Dr E. S. Anderson and staffs of the Salmonella and Central Enteric Reference Laboratories, Colindale, for their assistance in typing Salmonellae, and to a number of our colleagues who have kindly read the script and offered valuable criticisms.

\section{REFERENCES}

Bischотғ, J. (1956). Berl. Münch. tierärztl. Wschr. 69, 293.

Cherry, W. B., Scherago, M. \& Weaver, R. H. (1943). Amer. J. Hyg. 37, 211.

Galton, M. M., Lowery, W. D. \& Hardy, A. V. (1954). J. infect. Dis. 95, 232.

Galton, M. M., Smith, W. V., McElrath, H. B. \& HaRdy, A. B. (1954). J. infect. Dis. 95, 236.

Hormaeche, E. \& Salsamendi, R. (1936). Arch. urug. Med. 9, 665.

MoCullough, N. B. \& Eisele, C. W. (1951). J. infect. Dis. 89, 209.

Ministry of Health Reports on Public Health (1955). No. 96, H.M.S.O.

RePort (1947). Spec. Rep. Ser. med. Res. Coun., Lond., No. 260.

Report (1955a). Mon. Bull. Minist. Hlth Lab. Serv. 14, 132.

REPORT (1955b). Mon. Bull. Minist. Hlth Lab. Serv. 14, 203.

RePORT (1956). Mon. Bull. Minist. Hlth Lab. Serv. 15, 263.

Scott, W. M. (1940). Proc. R. Soc. Med. 33, 366.

(MS. received for publication 25. vII. .57) 